\title{
Islands, history, decolonial memory
}

\author{
May Joseph \\ Pratt Institute, USA \\ mjoseph@pratt.edu
}

\begin{abstract}
How do small island ecologies commemorate their disappeared pasts? What are some of the place-making practices that shape the formation of small island collective memories? Through the analysis of five case studies of small island communities in a comparative framework, this editorial introduction to a special section of Island Studies Journal on 'Islands, history, decolonial memory' opens up the mnemonic and psychoanalytic challenges facing contemporary island societies and the invention of their social memories. The islands of Balliceaux, Ro, Saaremaa, St. Simon and Dongzhou present competing instances of how memory operates across cultures of remembrance and forgetting.
\end{abstract}

Keywords: archipelagos, damnatio memoriae, decolonial, history, islands, lieux de mémoire, memory, mourning

https://doi.org/10.24043/isj.138 • Received November 2020, accepted November 2020

(C) 2020 - Institute of Island Studies, University of Prince Edward Island, Canada.

\section{Introduction: The speculative space of archipelagic writing}

Islands are memory disturbances (Le Goff, 1992). They are spectacles that evoke primal affects. Desire, fear, anxiety, silence, erasure, madness, carceral logics, pleasure. Their liminality, forged of sand, stone, rock, mist and ocean, draws one into the materiality of islandness. Surrounded by water, physically disconnected from larger continental influences, islands embody the neural spaces of memory. Their contours absorb the feelings a society imposes upon them. They also disrupt easy histories of mainland and islands, by remaining outside the frameworks of mainland narratives. Islands geologically interrupt the visual narrative of smooth seascapes, as well as the national narrative of what happened along the coasts of island societies. They demand a relational approach to the study of their ecologies and nonhuman histories (Pugh, 2018).

This special section of Island Studies Journal explores the processes through which societies remember (Connerton, 1989) or neglect small islands within national imaginaries that have been traumatized by colonization and slavery. It foregrounds studies in the mnemotechnologies of small island memory place making. These articles explore the contradictory and dualistic processes of commemorating and erasing public memories. They address how decolonial memory accrues or is submerged in specific island sites around the world (Gomez-Barris \& Joseph, 2019).

Memory is a corporeal practice in the activation of island history reclamation. It involves bodily engagement with decolonial exercises commemorating formerly colonized islands 
(Ricoeur, 2004). By decolonial, I mean the mnemotechnologies, acts, gestures and monuments through which histories of occupation are experienced and discursively addressed in the postcolonial period (Nadarajah \& Grydehøj, 2016; Aikau \& Gonzalez, 2019). Small islands with histories of occupation present very distinctive speculative spaces between land and sea, between near shore and deep ocean, between island and island (Grydehøj et al., 2015) where vernacular stories and mythic memories are dredged up in their repressed forms. Their relevance as formerly traumatized island spaces shifts and morphs alongside the porosity of their landscapes (Hau'ofa, 1993; Baldacchino, 2004). Fractal, fragmented and littoral, the sheer variety and multiplicity of these islands and their contested hidden memories open up the infinite possibilities for new kinds of archipelagic becoming (Schneider, 2020; Hadjimichael et al, 2020).

As Edouard Glissant (1997) shows us, the space of archipelagic thinking is the process of island writing. Abrasive, granulated and multiply striated like lines on a beach or granite cliffs, writing islands necessitates a sociology of speculative thought. It illuminates that which is discernible in the far horizon and the swash zone before one's line of sight, with all its wave action, floating debris, and undertow. One is drawn by the scales of finitude between berm, sea and horizon. Writing islands is a social science between hydrohumanities and lithology. One delves into the pebbles and gravels of history at the junctures of silt and ocean.

\section{Small island histories and the condemnation of memory}

This collection of articles deals with an obscure form of place unmaking in relation to memories of island spaces - that of the damnatio memoriae. Jacques Le Goff (1992) notes that the damnatio memoriae was an ancient Roman practice whereby the memory of an Emperor who had fallen from grace was deliberately destroyed through the erasure of monuments and archives ascribed to the individual. It involved the erasure of paintings and rooms in the individual's home. The domus or home of the disappeared Emperor was also erased. This technique, rooted in the Roman Senate, whereby the name and home of a tyrannical emperor were systematically erased from archival documents and monuments to counter the excesses of tyrants' power, has very few instances in contemporary history.

The articles here elaborate on how this practice of damnatio memoriae intersects with modern forms of historical erasure of small island pasts. They examine the unconscious and systematic ways in which certain kinds of violent social memories have morphed as living practice and mutated across different island cultural contexts. Unlike Roman times, however, these case studies of Ro, Balliceaux, Saaremaa, St. Simon, and Dongzhou present the informal yet deliberate mnemonic processes through which such memories of violent historical events are erased, even denied, in small island cultures. These alternative readings of the silencing of public memories that are inconvenient, shameful, and uncomfortable within the national imaginary, underscores how precarious access to the past is for small island societies internationally.

This special section presents specific small islands as performative social ecologies whose public histories have concealed the condemnation of specific local memories of slavery, occupation and forced migration. Nationalist narratives, fables, human actions, infrastructural developments and the engines of history merge here to portray a changing spectrum of island identities, island affects, island relationalities. They draw attention to the processual experiences of living and dying, of remembering and forgetting, of mourning and grieving, that structure these marginal islands, floating alongside continental landmasses. At the core, 
the terrible silence of damnatio memoriae, the official or unofficial but systematic erasure of these island histories inform these places of memory.

Dongzhou in Hengyang, China; Saaremaa in Estonia; Ro in Greece; Balliceaux in the Grenadines; and St. Simon Island off the coast of Georgia each present a distinctive case of how locales of decolonial memory remind of occupation, slavery and colonization. These liminal though unmarked places function as reminders of colonization, slavery and its aftermath. Together, these case studies offer a provocative rethinking of islands, mainlands and archipelagos in a postnational phase. They generate a speculative space of archipelagic thought, of thinking through the water in the wake of the ocean (Glissant, 1997; DeLoughrey, 2001; Roberts \& Stephens, 2017; Sharpe, 2014; Pugh, 2018; Joseph, 2019; King, 2019a, 2019b; Schneider, 2020). Submerged in the geology of foreshore, swamp, dunes and saltwater, they present a dialectic on the notion of lieu de mémoire of island histories (Nora, 1992).

These articles are interested in the speculative economies of uninhabited islands such as Balliceaux in the Caribbean, invisible islands such as Ro in the Aegean, traumatized islands such as Dongzhou in China, and fabulations like Igbo Landing in the U.S.. They throw open the substratum of island thinking enveloped in grief. As ecological entities separated from narratives of nationness that suture mainland societies, these traumatized island spaces are transformed into receptacles for repressed histories. Their terrain is filled with the thickness of accrued diasporic memory of violent island pasts that have been disappeared.

Balliceaux, Ro, Saaremaa, St. Simon and Dongzhou respectively demonstrate how bodily practices, commemorative acts and diasporic social memories create islands of mourning through active engagements with placeness. Their geographies are respectively contested spaces for interpretive place making. Their symbolic representations are simultaneously mythic and politically significant. These silenced islands are also critical players in economic geopolitical arrangements. They have become rhetorical spaces of memory and history, shaped by documented and erased events that have influenced their social construction as islands of loss.

These historically cursed islands of erased memories are palpable sites that Le Corbusier identifies as biological organisms (Kasinitz, 1995). They are living entities whose transformations from uninhabited to populated to evacuated, mark their own changing fascia as places where the human, the nonhuman and the more-than-human collide. They are particular historic spaces whose palimpsest timelines as crucibles of vernacular imagining have created encrusted traces of forgotten knowledges and embodied affect.

\section{Lieux de memoire and decolonial memories of island spaces}

The islands of Ro, Saaremaa, Dongzhou, St. Simon and Balliceaux are all small island ecologies that share histories of occupation and efforts at thinking through a decolonial moment (Finneran \& Welch, 2020; Hong, 2020). Each one of them are peripherally located in relation to their nation-state status. They raise the precarious balance between island as historical sign; island as morphing, embodied living site; and island as repository of mourning and memory. These places are foregrounded as islands whose sites of silenced memories are dynamized by processes of mnemotechnology (Le Goff, 1992), the journeys, acts, performative gestures and recounting that cultivate social memory across different sensorial registers. 
All five islands unpack genealogies of trauma and loss through which their differing histories of disappearance and memory revival emerge. They demonstrate the space between what Pierre Nora (1996) calls the lieux de memoire or memory places, and what Jacques Le Goff (1992) delineates as actio, or the performance of memory through gesture, like an actor. Applying the notion of memory places to the particular geological space of small island ecologies highlights how vulnerable many of these communities are to the condemnation of their local memories in contemporary times. These islands are scarred by the violence that produced their past (Hadjimichael et al, 2020; Schneider, 2020). The subsequent silences that have haunted them have shaped their practices of collective memory making, which in the case of the Balliceaux Island of the Garifuna peoples, is doubly displaced via the island of Roatan off the coast of Honduras.

Finneran and Welch's (2020) article on the tragic and violent dispersal of the Garifuna peoples from the Caribbean to the coast off Honduras, brings to prominence the challenges of narrating a simple accounting of the historic past. For the Garifuna peoples now scattered through Latin and North America, invoking the disappeared homeland of Yurumein is a diasporic performance of mourning, grieving and death. Forced out of their now-abandoned island home of Balliceaux in the late- $18^{\text {th }}$ Century, the Garifuna are haunted by a diasporic social memory they invoke on Roatan and in New York, of Yurumein, their originary home. The communal memory and grief that the Garifuna diaspora project onto the tiny uninhabited island in the Grenadines imbues the abandoned Balliceaux landscape with sacred qualities. For the Garifuna, Balliceaux is a place of mourning.

The case of Balliceaux demonstrates the multidirectional structures of interruptions and disturbances that unfold across small island ecologies, in this case from the Grenadines, to Roatan to the archipelago of New York City (Rothberg, 2009). The story of Garifuna social memories conjures landscapes of affective imaginings and forgotten landscapes. Their lived histories as island peoples collides with their conflicted national imaginaries, and silenced pasts. The abandoned locales that constitute their places of mourning and remembrance on Balliceaux become spaces where new possibilities open up to comprehend the shifting sands of networked island histories through which Garifuna social memories are constituted.

What threads these different articles are the discursive actions of commemoration and social memory through which their respective vernacular histories are situated. These islands are mental bridges to imagined and real connectivities as in the case of the island of Saaremaa (Raadik Cottrell \& Cottrell, 2020). They are also deeply isolated locales of violence and national forgetting as demonstrated in the searing case of Dongzhou (Hong, 2020). Their different histories are conjoined through the experience of colonization and/or disappearance. They explore the fluid ecologies of the wrack line and striated sedimentation through which memory, heritage, trauma and the littoral contours of beaches merge and wash over each other in the production of living histories out of which that which is nameable as well as that which is unknowable are contended with (Schneider, 2020).

Amidst the ephemerality of island geologies presented here, eroding shorelines and stormy seafronts demonstrate that islands are what Gayatri Spivak (2003) invokes as microcosms of planetarity. They are fragments of subterranean materiality and geological-becoming. Their visual prominence distinguishes their peculiar histories as crucibles of planet making. The islands of Ro, Dongzhou, St. Simon, Balliceaux and Saaremaa pulse as sites of island mourning, as emblems of memory practice. They are peripheral floating worlds whose ecology, climate, 
human and nonhuman entanglements forge a symbiotic web in the making, where bones, graves, ghosts, storytelling and stones encrust islandographies (Hadjimichael et al, 2020).

These articles in mourning suggest that island histories "simply could not be ours to know" as Rebecca Schneider (2020) remarks in her performative article about retracing mythic journeys in search of a new body of re-accounting, of coming to consciousness, of knowledge making. And yet, these islands of history compel a return, a rememoring to that originary moment of a Garifuna social memory (Finneran \& Welch, 2020), an African American cultural memory (Schneider, 2020), an Ottoman mythic memory (Hadjimichael et al, 2020), a Chinese repressed memory (Hong, 2020) and an Estonian public memory (Raadik Cottrell \& Cottrell, 2020).

\section{Mnemotechnologies and social memory}

Why are islands such liminal places of inquiry? What is it about their locatedness, rock, stone, sand and earth extruding out of the ocean that makes these geological events powerful "memory places" (Nora, 1992)? How might one begin to discern between displaced individual memory (Nora, 1992) and hegemonic social memory (Halbwachs, 1992) in the process of writing islandographies (Hadjimichael et al, 2020)? These are the persuasive lines of probing that drive Gang Hong's (2020) article about the tiny island of Dongzhou in the Xiangjiang River.

Preoccupied with the legacies of trauma memory and what that might mean for island spatiality, Gang Hong (2020) elaborates on Halbwachs' concept of social memory to present ideas of hard and soft island memory versus lived island memory. What concerns Hong is the history of Dongzhou's occupation by the Japanese during the Second World War, and the atrocities they committed on the island. Hong argues that addressing place memory in sites of trauma such as Dongzhou necessitates multidirectional strategies of inventing memory places (Rothberg, 2009). Hong points out that the rupture between island representation and island experience stages the gap between consuming and remembering. Hong discerns multiple layers of mnemonic place making. Geographical memory is normative through its production of islandness delineated through the aspects of boundedness, smallness, isolation and littorality (Kelman, 2020). But invoking traumatic memories, Hong argues, demands a far more nuanced approach that has not yet been contemplated by the local government authorities responsible for Dongzhou. Hong makes a plea for a cultural rethinking of Dongzhou's island history, and asks what constitutes heritage. Hong wonders whether alternative representations that address the violence and trauma of Dongzhou are at all possible in the face of Dongzhou's reinvention as a heavy tourist site, and he questions what authentic memories might mean in the light of the heavily mediated collective memories being projected onto Dongzhou.

"Island studies is itself an important decolonial venture," write Yaso Nadarajah and Adam Grydehøj (2016, p. 441). It demands a different aesthetics, one that Hadjimichael et al. (2020) propose as a geopoetics. In sympathy with Hong's disillusionment regarding the fate of Dongzhou's buried traumatic past, Hadjimichael, Constantinou and Papaioakeim throw open an archive offering durational perspectives on forgotten or peripheral histories of social memory forming the island of Ro in Greece. They grapple with a methodology of how to reimagine island space in the aftershock of occupation, contested island ownership and border wars 
(Stephens, 2013). We are drawn into biographies of islands (Hadjimichael et al, 2020). Islands are living entities. What kinds of identities do islands have? How do islands become islands?

Godfrey Baldacchino's (2008) call to disentangle and diversify island histories shapes the multidirectional memories of these diverse articles. Reclaiming island histories out of the darkness of saltwater colonialism, as Hadjimichael et al. (2020) argue, demands a move beyond a Western-centric thinking. They propose applying geopoetics (Balasopoulos, 2008) as a technique of reclaiming island histories.

Rebecca Schneider's (2020) article demonstrates what such a geopoetics of reclaiming island histories might entail. It is a performative journey of palimpsest history. Part self ethnography, part ocean archaeology, she retraces a historic past through a sea journey in the wake of an apocryphal tale, that of Igbo Landing. Schneider skillfully immerses herself in the unpredictable waters of littoral zones off the coast of the Carolinas to dredge what she can of her own unlearning. She dives into the icy currents of African American history to probe the shoals of seafaring accounts. Building on Jonathan Pugh's (2016) query as to what liminality and performance might offer an island studies methodology, Schneider excavates a living myth through the deep practice of ethno-ecology. Searching the ethnic histories of coastal ecologies and their silenced historic significances, Schneider's performative writing stages a reengagement with this apocryphal American story of arrival, at once the archetypal story of freedom and free will. Schneider's article is a performance of the archive and the repetition. Of history and its mythic iterations. She cathects through Tiffany Lethabo King's (2019a, 2019b) prism of the shoal and opens up the gap between the known and the misreading, through which those outside the history of slavery share the legacies of that symbiotic past.

In closing, this issue on the phenomenology of memory place making on small island ecologies brings together islands from China, Turkey and Greece, the United States, Estonia, and the Caribbean. It foregrounds the challenges of contesting national memories and reviving repressed local histories at the expense of rising real estate values and government development plans. These islands of the forgotten in a comparative frame share the experience of occupation, colonization and slavery in different registers. Their respective struggles to create social memories of trauma and disappearance, displacement and forced migration, genocide and death is a history that merits a new awareness at the level of local cultures as well as at the level of international heritage sites and national policies of cultural recognition. As instances of island social memories, these poignant examples of tiny islands that have been culturally disappeared or ignored present the ethical issue of precarity and public recognition of the silenced memories of small island societies across the world.

\section{References}

Aikau, H., \& Gonzalez, V. (2019). Curating a decolonial guide: The Detours Project. Shima, 13(2), 11-21. https://doi.org/10.21463/shima.13.2.04

Baldacchino, G. (2008). Studying islands: On whose terms? Some epistemological and methodological challenges to the pursuit of island studies. Island Studies Journal, 3(1), 37-56.

Baldacchino, G. (2004). The coming of age of island studies. Tijdschrift voor economische en sociale geografie, 95(3), 272-283. https://doi.org/10.1111/j.1467-9663.2004.00307.x

Connerton, P. (1989). How societies remember. Cambridge University Press. 
DeLoughrey, E. (2007). Routes and roots: Navigating Caribbean and Pacific island literatures. University of Hawaii Press. https://doi.org/10.1515/9780824864187

Finneran, N., \& Welch, C. (2020). Mourning Balliceaux: Towards a biography of a Caribbean island of death, grief and memory. Island Studies Journal, 15(2), 255-272. https://doi.org/10.24043/isj.121

Glissant, E. (1997). Poetics of relation. University of Michigan Press.

Gomez-Barris, M., \& Joseph, M. (2019). Coloniality and islands. Shima, 13(2), 1-10. https://doi.org/10.21463/shima.13.2.03

Grydehøj, A., Barcelo Pinya, X., Cooke, G., Doratli, N., Elewa, A., Kelman, I., Pugh, J., Schick, L., \& Swaminathan, R. (2015). Returning from the horizon: Introducing urban island studies. Urban Island Studies, 1, 1-19. https://doi.org/10.20958/uis.2015.1

Hadjimichael, M., Constantinou, C.M., \& Papaioakeim, M. (2020). Imagining Ro: On the social life of islets and the politics of islandography. Island Studies Journal, 15(2), 219236. https://doi.org/10.24043/isj.123

Halbwachs, M. (1992). On collective memory. University of Chicago Press.

Hau'ofa, E. (1994). Our sea of islands. Contemporary Pacific, 6, 148-161.

Hong, G. (2020). Islands of memory, islands of trauma: The case of Dongzhou, Hengyang, China. Island Studies Journal, 15(2), 237-254. https://doi.org/10.24043/isj.131

Joseph, M. (2019). Sea log: Indian Ocean to New York. Routledge.

King, T.L. (2019a). The Black shoals: Offshore formations of Black and Native studies. Duke University Press. https://doi.org/10.1515/9781478005681

King, T.L. (2019b). Off littorality (shoal 1.0): Black study off the shores of 'the Black body'. Propter Nos, 3, 40-50.

Le Corbusier (1995). New York is not a completed city. In P. Kasinitz (Ed.), Metropolis: Center and symbol of our times. New York University Press.

Le Goff, J. (1992). History and memory. Columbia University Press.

Nadarajah, Y., \& Grydehøj, A. (2016). Island decolonization: Island studies as a decolonial project. Island Studies Journal, 11(2), 437-446.

Nora, P. (1996). Realms of memory: The construction of the French past. Columbia University Press.

Pugh, J. (2018). Relationality and island studies in the Anthropocene. Island Studies Journal, 13(2), 93-110. https://doi.org/10.24043/isj.48

Raadik Cottrell, J., \& Cottrell, S.P. (2020). In spaces in between - From recollections to nostalgia: Discourses of bridge and island place. Island Studies Journal, 15(2), 273-290. https://doi.org/10.24043/isj.133

Ricoeur, P. (2004). Memory, history, forgetting. University of Chicago Press.

Roberts, B.R., \& Stephens, M. (Eds.) (2017). Archipelagic American studies. Duke University Press.

Rothberg, M. (2009). Multidimensional memory: Remembering the Holocaust in the Age of Decolonization. Stanford University Press. https://doi.org/10.1017/s0395264900007757

Schneider, R. (2020). This shoal which is not one: Island studies, performance studies, and Africans who fly. Island Studies Journal, 15(2), 201-218. https://doi.org/10.24043/isj.135

Sharpe, C. (2016). In the wake: On Blackness and being. Duke University Press. 
May Joseph 